\title{
Primary immunisations in Liverpool. I: Who withholds consent?
}

Maggie Pearson, Krystyna Makowiecka, Jacqueline Gregg, Jane Woollard, Michael Rogers, Chris West

\begin{abstract}
The association between parents in Liverpool consenting to their children being invited for primary immunisations and five sociodemographic factors, namely sex, position of child in the family, family type, migration into Liverpool since birth, and local deprivation was examined. Rates of consent to invitation were over $97 \%$ for each antigen except pertussis, which had a consent rate of $83 \%$. Consent to invitation for pertussis vaccine was least likely to have been given for boys, children with older siblings, those recorded as living with a single parent, and those in the most deprived areas. Local deprivation also had an effect on consent to the measles, mumps, and rubella vaccine. Migration into Liverpool had a significant effect on consent to invitation for all antigens except pertussis. The child's sex, family type, and local deprivation had no effect on consent to diphtheria, tetanus, and polio immunisations.
\end{abstract}

Maximising pertussis vaccine uptake will require more attention to be paid to those parents who have been identified as being less likely to give consent. It is particularly important that consistent and clear advice about immunisations is made available to parents with two or more children, lone parents, and those living in materially deprived areas. Our findings challenge some of the assumptions underlying the principles of 'first parent visiting', at least so far as pertussis is concerned.

(Arch Dis Child 1993; 69: 110-114)

The drive to maximise the rate of childhood immunisation has been given renewed emphasis with the introduction of target payments in the 1990 general practitioner contact ${ }^{1}$ and the suggestion of targets of 95\% uptake for England and Wales by $1995 .{ }^{2}$ Despite much research on immunisation rates, ${ }^{3-7}$ scant attention has been paid to a key component of uptake, namely obtaining consent from parents. As targets are set ever higher, children whose parents decline all immunisations, or that of specific antigens, will become increasingly significant for target attainment. Moreover, defining more precisely the relative importance of consent should facilitate more effective immunisation strategies and the targeting of educational and information resources to maximise the protection of children's health.

The Peckham Report stands alone in reporting rates of consent to inclusion in a call and recall system for invitations to immunisation. ${ }^{4}$ In the 16 district health authorities studied, only $0.4 \%$ of parents did not consent to their child's inclusion in the system. Antigen specific consent rates were not discussed, however. Professional advice against immunisation with measles and pertussis vaccines, and the association between parents' attitudes and their child's uptake of pertussis and measles immunisations were considered only in the context of completion rates.

Immunisation course completion rates have been shown to be associated with several factors, which fall into two broad categories: characteristics and circumstances of individual children and their families ${ }^{45-11}$ and the characteristics of the service arrangements under which immunisations are offered. ${ }^{34912}$ The two sets of factors have been shown to have an independent effect on immunisation rates, ${ }^{4}$ but their impact on the two separate components of uptake has not been identified: on the one hand, consent to invitation for immunisation with specific antigens; and on the other, completion of courses among those who so consented. Furthermore, no previous studies have examined antigen specific consent rates.

In the course of a detailed study of primary immunisations in Liverpool, we became aware that the distinction between consent and completion could have important practical implications for effective strategies to improve uptake rates. In this paper, therefore, we identify and discuss the effect of children's social and family circumstances on consent. In other words, who is likely or unlikely to give consent, and for which antigens? In a second paper ${ }^{13}$ we identify and discuss the effect of those factors on completion of immunisation courses: that is to say, once consent has been obtained, which factors influence completion?

\section{Subjects and methods}

The immunisation records of individual children born between 1 April and 1 October 1988 inclusive and resident within Liverpool District Health Authority in September 1991 were obtained from data on the vaccination and immunisation module of the National Child Health System. This cohort was selected for several reasons. Firstly, their primary immunisations should have been completed when the new general practitioner contract, with its target payments, was introduced in April 1990.' Secondly, all children in the cohort would have been offered the measles, mumps, and rubella (MMR) vaccine. Thirdly, at the time of data extraction, there should have been sufficient time for all data on the child's primary course and MMR immunisation history to be recorded on the regional computer. 
These children would have been invited to receive diphtheria, tetanus, polio, and pertussis immunisations at 3,5, and 8 months, and the MMR vaccine at 1 year of age. In addition to details of a child's immunisation history (including the consent code which indicated the specific antigens for which consent was given), data on five sociodemographic variables were also extracted. These variables were: the child's sex, family position (inferred from mother's parity at child's birth), recorded family type (lone parent or two parent), migration into Liverpool since birth, and current electoral ward. Data on ethnic origin and parents' social class were not available on the computer records.

The overall deprivation index $(\mathrm{ODI})^{14}$ of the child's electoral ward was derived from their postcode. The ODI, an indicator of material deprivation, combines four 1981 census variable indicators: unemployment, car ownership, home ownership, and overcrowding. It is a more accurate index of socioeconomic conditions than the Jarman underprivileged area score, ${ }^{15}$ which includes other demographic variables and is an indicator of general practitioners' workload. ${ }^{16}$ Electoral wards' ODI scores varied from $-2 \cdot 82$ (least deprived) to 9.67 (most deprived). The national average score is 0 . For descriptive purposes wards were divided on the basis of their scores into 'least deprived' with ODI scores between $-2 \cdot 82$ and $3 \cdot 12$; 'deprived', with scores between 3.13 and 5.98; and 'most deprived', with scores between 5.99 and 9.67 .

The data were downloaded onto a microcomputer and analysed using the Epi-Info statistical package ${ }^{17}$ to calculate antigen specific and 'composite' (all antigens) consent rates by the child's sex, family position, family type, migration, and local (ward) deprivation category. As preliminary data analysis confirmed that consent to invitation for diphtheria, tetanus, and polio (DTPol) were almost identical, these three antigens are reported together, whereas pertussis and MMR immunisation were considered separately. $\chi^{2}$ Tests (including for trend) for significance of the simple association of individual factors with consent rates were undertaken using the Arcus package. ${ }^{18}$ The SAS statistical package ${ }^{19}$ was used to fit logistic regression models ${ }^{20}$ to the data to assess the independent strength of association of each individual factor with consent, after controlling for the effect of the other factors. For each variable, odds ratios were calculated of consent being given to each antigen or antigen group. An odds ratio of unity indicates that there is no association between the variable and consent. Any variable for which the $95 \%$ confidence limits include a value of unity are thus considered not to have a significant effect on consent.

\section{Results}

RATES OF CONSENT TO INVITATION FOR IMMUNISATION

Of the cohort of 3585 children (1714 girls, 1871 boys), consent to invitation for immunisation was not given for $13(0.4 \%)$ and was withdrawn for a further $15(0 \cdot 4 \%)$. The consent code was not recorded for $23(0 \cdot 6 \%)$. Consent was given to invitation for all antigens for 2941 (82.0\%) children, and for all antigens except pertussis for a further $521(14.5 \%)$ children. Of the remaining $72(2 \cdot 0 \%)$ children, consent was given for single or other combinations of antigens.

Table 1 shows the consent rate for each individual antigen. The consent rate was over $97 \%$ for each antigen except pertussis, for which $17 \%$ of parents chose not to have their child invited.

\section{VARIABLES ASSOCIATED WITH CONSENT}

Each of the five sociodemographic variables was significantly associated with consent to be invited for the full set of antigens (table 2). Statistically, full consent was less likely to be given for boys, for children recorded as living with a lone parent, and for children who moved into the Liverpool health district after birth. Full consent decreased sharply with an increasing number of older siblings and with increasing material deprivation.

Consent to pertussis antigen also showed a significant association with each of the five variables. Consent to DTPol or MMR was affected by postnatal migration into Liverpool and by ward deprivation, but not by sex, family position, or family type.

\section{INDEPENDENT EFFECT OF SOCIODEMOGRAPHIC} VARIABLES

Table 3 shows the independent effect on consent to invitation for immunisation with the full set of antigens and to individual antigens of each of the five variables: the child's sex, family position, family type, migration after birth into the district, and deprivation category of ward of residence.

Migration into Liverpool was the only variable to have an independent effect on consent to DTPol (table 3). Children who had moved into Liverpool since birth were also highly unlikely to have had consent recorded for invitation for the MMR vaccine. Sex and family type had no independent effect on consent to DTPol or MMR. Family position had no independent effect on consent to DTPol, and was significant only for the fourth and later children on consent to MMR. Ward deprivation score had a significant effect on consent to MMR, but not for DTPol.

Pertussis was the only antigen for which sex had a significant independent effect on consent, consent being more likely to be given for girls than for boys (table 3 ). In contrast, pertussis was the only antigen for which migration into the Liverpool health district had no significant independent effect on consent. Family position,

Table 1 Composite and antigen specific initial consent rates

\begin{tabular}{ll}
\hline Antigen & No $(\%)$ consent rate recorded $(n=3585)$ \\
\hline Diphtheria & $3511(97 \cdot 9)$ \\
Tetanus & $3514(98 \cdot 0)$ \\
Polio & $3517(98 \cdot 1)$ \\
Pertussis & $2976(83 \cdot 0)$ \\
MMK & $3481(97 \cdot 1)$ \\
All antigens & $2941(82 \cdot 0)$ \\
\hline
\end{tabular}


Table 2 Sociodemographic factors and consent to invitation for primary immunisations

\begin{tabular}{|c|c|c|c|c|}
\hline \multirow[b]{2}{*}{ Factor } & \multicolumn{4}{|c|}{ Consent rate $(\%(\mathrm{No}))$} \\
\hline & DTPol & Pertussis & $M M R$ & All antigens \\
\hline Sex & & $\star \star \star$ & & $\star \star$ \\
\hline Girls & $97 \cdot 3(1667 / 1714)$ & $84 \cdot 8(1453 / 1714)$ & $97 \cdot 0(1663 / 1714)$ & $83 \cdot 6(1433 / 1714)$ \\
\hline Boys & $98 \cdot 0(1833 / 1871)$ & $81.9(1532 / 1871)$ & $97 \cdot 2(1818 / 1871)$ & $80 \cdot 6(1508 / 1871)$ \\
\hline Family position ${ }^{\star}$ & & & & \\
\hline First child & $98 \cdot 2(1382 / 1408)$ & $88 \cdot 3(1243 / 1408)$ & $97.9(1379 / 1408)$ & $87 \cdot 5(1232 / 1408)$ \\
\hline Second child & $99 \cdot 1(1149 / 1159)$ & $83.7(970 / 1159)$ & $97 \cdot 3(1128 / 1159)$ & $82 \cdot 4(955 / 1159)$ \\
\hline Third child & $98 \cdot 8(554 / 561)$ & $76 \cdot 3(428 / 561)$ & $97.7(548 / 561)$ & $75 \cdot 9(426 / 561)$ \\
\hline Fourth child and above & $97 \cdot 2(351 / 361)$ & $74 \cdot 0(267 / 361)$ & $96 \cdot 7(349 / 361)$ & $74 \cdot 0(267 / 361)$ \\
\hline Family typet & & $\star \star \star$ & & $\star \star \star$ \\
\hline Lone parent & $98 \cdot 1(1247 / 1271)$ & $80 \cdot 4(1022 / 1271)$ & $97 \cdot 7(1242 / 1271)$ & $79 \cdot 8(1014 / 1271)$ \\
\hline Two parents. & $98 \cdot 5(2156 / 2188)$ & $85 \cdot 0(1860 / 2188)$ & $97 \cdot 4(2131 / 2188)$ & $84 \cdot 1(1840 / 2188)$ \\
\hline Migration into Liverpool & $\star \star \star$ & & $\star \star \star$ & $\star \star \star$ \\
\hline Resident at birth & $98 \cdot 7(3252 / 3294 /$ & $83 \cdot 5(2749 / 3294)$ & $98 \cdot 1(3232 / 3294)$ & $82 \cdot 9(2732 / 3294)$ \\
\hline Moved in since birth & $88 \cdot 7(258 / 291)$ & $78 \cdot 0(227 / 291)$ & $85 \cdot 6(249 / 291)$ & $71 \cdot 8(209 / 291)$ \\
\hline Deprivation $\ddagger$ & 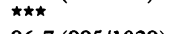 & & $\star \star \star$ & \\
\hline $\begin{array}{l}\text { Most deprived } \\
\text { Deprived }\end{array}$ & $\begin{array}{l}96 \cdot 7(995 / 1029) \\
98 \cdot 3(1194 / 1215)\end{array}$ & $\begin{array}{l}78 \cdot 2(805 / 1029) \\
83 \cdot 9(1019 / 1215)\end{array}$ & $\begin{array}{l}95.9(987 / 1029) \\
97 \cdot 0(1178 / 1215)\end{array}$ & $\begin{array}{l}77 \cdot 1(793 / 1029) \\
82 \cdot 8(1006 / 1215)\end{array}$ \\
\hline Least deprived & $98 \cdot 4(1148 / 1167)$ & $85.9(1003 / 1167)$ & $97.9(1142 / 1167)$ & $85 \cdot 1(993) 1167)$ \\
\hline
\end{tabular}

$\star$ Data missing for 96 cases.

†Data missing for 126 cases.

Data missing for 174 cases.

${ }_{\star}$ Difference significant, $0.01<p<0.05 ;{ }^{\star \star \star}$ difference highly significant, $p<0.01$

Table 3 Independent odds ratio (OR) (95\% confidence interval (CI)) for each factor of consent being given for specific and groups of antigens estimated from logit model

\begin{tabular}{|c|c|c|c|c|}
\hline Factor & $\begin{array}{l}D T P o l^{\star}(O R \\
(95 \% C I))\end{array}$ & $\begin{array}{l}\text { Pertussist (OR } \\
(95 \% \text { CI }))\end{array}$ & $\begin{array}{l}M M R \mp(O R \\
(95 \% C I))\end{array}$ & $\begin{array}{l}\text { All antigens } \delta(O R \\
(95 \% C I))\end{array}$ \\
\hline \multicolumn{5}{|l|}{ Sex } \\
\hline Boys & & $1 \cdot 0$ & 1.0 & \\
\hline Girls & $1 \cdot 11(0.63$ to 1.95$)$ & $1 \cdot 26(1.04$ to 1.52$)$ & $1 \cdot 16(0.73$ to $1 \cdot 84)$ & $1.23(1.02$ to 1.48$)$ \\
\hline \multicolumn{5}{|l|}{ Family position } \\
\hline First child & & & & $1 \cdot 0$ \\
\hline Second child & $1.67(0.78$ to 3.56$)$ & $0.59(0.46$ to 0.74$)$ & $0.64(0.37$ to $1 \cdot 13)$ & $0.57(0.45$ to 0.72$)$ \\
\hline Third child & $1.12(0.47$ to 2.67$)$ & $0.38(0.29$ to 0.5$)$ & $0.73(0.35$ to 1.48$)$ & $0.39(0.30$ to 0.51$)$ \\
\hline Fourth child and above & $0.5(0.23$ to 1.09$)$ & $0.34(0.25$ to 0.46$)$ & $0.46(0.22$ to 0.96$)$ & $0.36(0.26$ to 0.49$)$ \\
\hline \multicolumn{5}{|l|}{ Family type } \\
\hline Two parents & $1 \cdot 0$ & $1 \cdot 0$ & & $1 \cdot 0$ \\
\hline Lone parent & $0.73(0.4$ to 1.31$)$ & $0.63(0.52$ to 0.77$)$ & $1 \cdot 1(0.67$ to 1.8$)$ & $0.65(0.53$ to 0.79$)$ \\
\hline \multicolumn{5}{|l|}{ Migration into Liverpool } \\
\hline Resident at birth & & $1 \cdot 0$ & $1 \cdot 0$ & $1 \cdot 0$ \\
\hline Moved in since birth & $0.21(0.1$ to 0.45$)$ & $0.78(0.5$ to 1.2$)$ & $0.14(0.08$ to 0.25$)$ & $0.6(0.4$ to 0.9$)$ \\
\hline \multicolumn{5}{|l|}{ Deprivation } \\
\hline Per ODI unit & $0.92(0.83$ to 1.02$)$ & $0.94(0.91$ to 0.97$)$ & $0.9(0.83$ to 0.98$)$ & $0.94(0.91$ to 0.97$)$ \\
\hline
\end{tabular}

$\star$ Likelihood ratio $\chi^{2}=32 \cdot 14$, with $7 \mathrm{df}, \mathrm{p}<0 \cdot 0001$

tLikelihood ratio $\chi^{2}=110 \cdot 47$, with $7 \mathrm{df}, \mathrm{p}<0.0001$

tLikelihood ratio $\chi^{2}=65 \cdot 2$, with $7 \mathrm{df}, \mathrm{p}<0.0001$.

†Likelihood ratio $\chi^{2}=65 \cdot 2$, with $7 \mathrm{df}, \mathrm{p}<0 \cdot 0001$
\$Likelihood ratio $\chi^{2}=107 \cdot 20$, with $7 \mathrm{df}, \mathrm{p}<0 \cdot 0001$

family type, and ODI score each had significant independent effects on consent to pertussis, so that children with older siblings, those living with a lone parent, and those living in more materially deprived wards were less likely to have had consent given.

\section{Discussion}

In Liverpool, consent to immunisation is sought by the health visitor when the child is approximately 10 days old. As she is often the first health professional to discuss immunisations with parents, the health visitor is in a key position of influence in obtaining consent, but general practitioners will become increasingly significant as they become more involved in preventive child health care. Regular training and updating is important for all professionals to ensure that consistent advice is given. For example, it has been suggested that neither the public nor health professionals have been given clear guidance on the safety of immunisations when the child has an intercurrent (or previous) illness. ${ }^{4} 121$

Previous research has identified several child related factors as significant influences on immunisation course completion rates. These factors include family position, ${ }^{45}$ socioeconomic deprivation and social class, ${ }^{458922}$ and area of residence. ${ }^{79}$ There is, however, conflicting evidence as to whether children who move between health districts during the immunisation period are less likely to be fully immunised. ${ }^{72-25}$ Our research indicates that each of these factors had a significant effect on consent to invitation for the full course of primary immunisations, and to specific antigens, among the children studied. The nature of the data, however, prevented exploration of the influence on consent of other factors identified as significant in immunisation completion: racial/ethnic group, ${ }^{1011}$ acute and chronic illness in the child or other members of the family,,$^{45}$ and beliefs, fears, and scepticism about 'needles' and immunisations against diseases which most parents will never have encountered. ${ }^{45}$

In our cohort of children, the rate of consent to the pertussis vaccine was low. Clearly, despite optimism that national targets of $95 \%$ coverage are realistic for $1995,{ }^{6}$ they will not be achieved in Liverpool until a greater proportion of parents give consent. Professional advice to parents is likely to reflect the degree of misunderstanding in primary care about precise contraindications 
to the vaccine, ${ }^{421}$ not helped by mixed and inconsistent messages from family and friends.

Several factors were associated with the withholding of consent to immunisation against pertussis: older siblings, lone parents, living in materially deprived areas, and the child being male. The decline in consent to pertussis with later family position may reflect a cohort effect associated with increasing parental experience. Previous children may have been perceived as having reacted adversely to the vaccine. Also, if older non-immunised children escape the clinical disease, ${ }^{5}$ or cope with a mild attack, the perceived risks of the pertussis vaccine may outweigh the apparent benefits, particularly to parents old enough to remember the 1970's scare. Recent changes in official advice and guidelines may cause confusion or provoke scepticism among older parents. Many districts now concentrate health visiting on first children, ${ }^{26}$ but our data indicate that it cannot be assumed that willingness to give consent will be carried over from the first to subsequent children, particularly for pertussis.

No previous studies have explored the influence of family type on consent to, or completion of, immunisations. The significant independent influence of recorded family type on consent to the full set of antigens, and particularly to pertussis, merits further careful investigation. Future studies need to have clear criteria for definition as a 'one parent family', and to take account of the heterogeneity of lone parents, most of whom are lone mothers, who may be single, divorced, separated, or widowed. ${ }^{27}$ Generally, however, lone mothers are younger, have fewer formal educational qualifications, and are more likely to be living on income support than women living with their children and with male partners. ${ }^{28}$ Other studies have established these circumstances as associated with a lower uptake of preventive health services, the longer term benefits of which may be outweighed by competing short term demands on the lone parent's time and resources. ${ }^{29}$

Greater local material deprivation was significantly associated with withholding of consent to pertussis and MMR immunisations. Particular care may be needed to ensure that parents living in materially deprived areas are given sound information and advice about the risks and benefits of all immunisations, so that they can make a truly informed choice on behalf of their child.

The significant sex difference in consent to pertussis is surprising, and the reasons are not clear. Although there are more boys than girls among survivors of neonatal special care, ${ }^{30}$ we consider that neonatologists are likely to emphasise the importance of pertussis immunisation (except when valid contraindications apply). It is possible to speculate that the sex difference reflects parents' greater concern about the risk of brain damage to sons than daughters.

The least reliable records in this cohort are likely to be those of children who moved into Liverpool. Their recorded consent rates may thus be 'fictional', ${ }^{25}$ in part at least, reflecting problems of information transfer between health districts. ${ }^{23}$ Incomplete data transfer may explain why migration was the only variable to have an independent effect on recorded consent to DTPol. Compatible computer systems would help to overcome this problem. It is also possible, however, that parents who move into the district do not establish the same rapport with health visitors and other primary care staff who were not involved with their pregnancy and postnatal care. Health visitors see the 'birth visit' as a key factor in gaining and maintaining entry to households. ${ }^{31}$

In conclusion, our findings suggest that successful immunisation strategies will need to address several practical issues related to consent: (a) staff training should aim to provide consistent and authoritative advice to parents about immunisation; (b) improving consent rates for pertussis immunisation must be a priority; (c) serious consideration should be given to differential resource allocation, particularly of health visitor time, to target materially deprived areas and families with two or more children, with consistent advice and support; and (d) the reliability of immunisation data transfer when families move to another health district should be investigated.

Particular thanks to the Royal Liverpool Children's Hospital NHS Trust Research Review Group for financial support; to Mr R Morley, Mersey Regional Health Authority for support and advice in respect of the data; to Dr J L Hutton and Dr D Ashby for their invaluable advice on statistical analysis; and to the City of Liverpool Planning Department for the ward ODI data.

1 Health Departments of Great Britain. General practice in the National Health Service: the 1990 contract. London: DepartNational Health Service: the 1990 contract. Lor

2 Secretary of State for Health. The health of the nation. London: HMSO, 1991

3 Nicoll A, Elliman D, Begg NT. Immunisation: causes of failure and strategies and tactics for success. $B M \mathcal{F} 1989 ; 299$ : 808-12.

4 Peckham C, Bedford H, Senturia Y, Ades A. National immunisation study: factors influencing immunisation uptake in
childhood. London: Action Research for the Crippled Child,
1989. (The Peckham report.)

New SJ, Senior ML. 'I don't believe in needles': qualitative aspects of a study into the uptake of infant immunisation in two English health authorities. Soc Sci Med 1991; 33: 509 18.

6 White JM, Gillam SJ, Begg NT, Farrington CP. Vaccine coverage: recent trends and future prospects. $B M F$ 1992; 304: $682-4$.

$7 \mathrm{Li} \mathrm{J}$, Taylor B. Comparison of immunisation rates in genera practice and child health clinics. BMF 1991; 303: 1035-8.

$8 \mathrm{Marsh}$ GN, Canning DM. Deprivation and health in one general practice. $B M \mathscr{F}$ 1986; 292: $1173-6$.

9 Jarman B, Bosanquet N, Rice P, Dollimore N, Leese B. Uptake of immunisation in district health authorities in England. BMF 1988; 29: 2775-8.

10 Baker MR, Bandaranayake R, Schweiger MS. Differences in rate of uptake in immunisation among ethnic groups. $B M \mathcal{F}$ 1984; 288: 1075-8.

11 Bhopal RR, Samin A. Immunisation uptake of Glasgow Asian children: benefits of the communication barrier. Community Med 1988; 10: 215-20.

12 Carter H, Jones IG. Measles immunisation: results of a local programme to increase vaccine uptake. $B M F$ 1985; 290: 1717-9.

13 Pearson $\dot{M}$, Makowiecka K, Gregg J, Woollard J, Rogers M, West C. Primary immunisations in Liverpool. II: Is there a gap between consent and completion? Arch Dis Child 1993; ownsend $P, 1$

inequality and the North. London: Croom Helm, 1988.

15 Jarman B. Identification of underprivileged areas. BMF 1983; 286: 1705-8.

16 Morris R, Carstairs V. Which deprivation? A comparison of selected deprivation indexes. $\mathcal{F}$ Public Health Med 1991; 13: 318-26.

17 Dean AD, Dean JA, Burton JH, Dicker RC. Epi-Info, version 5: a word processing, database and statistics program for epidemiology on microcomputers. Atlanta: Centers for Disease

18 Buchan I. Arcus Version 5.0. Users' booklet. Aughton: Medical Computing, 1989

19 SAS Institute. SUCI supplemental library user's guide, version 5 edn. Cary, NC: SAS Institute, 1986: Ch 23. 
20 Matthews DE, Farewell VT. Using and understanding medical statistics. Basle: Karger, 1985.

21 Nicoll A, Jenkinson D. Decision making for routine measles/ $M M R$ and whooping cough immunisation. $B M \mathcal{F} 1988 ; 297$ 405-7.

22 Gatrell A. Immunisation against whooping cough in Salford: a spatial analysis. Soc Sci Med 1986; 23: 1027-32.

23 Mant D, Phillips A, Knightley M. Measles immunisation rates and the good practice allowance. $B M \mathcal{F} 1986 ; 293$ : $995-7$.

24 While A. Child health clinic attendance during the first two years of life. Public Health 1990; 104: 141-6.

25 Jeffries S, McShane S, Overton J, Victor C, Beardow R. Low immunisation uptake rates in an inner-city health district: fact or fiction? F Public Health Med 1991; 13: 312-8.
26 Barker W. Child development programme. Bristol: Early Childhood Development Unit, University of Bristol, 1984. 27 Haskey J. One parent families in Britain. Population Trend 1986; 45: 5-13.

28 Popay J, Jones G. Patterns of health and illness amongst lone parents. Fournal of Social Policy 1990; 19: 499-534.

29 Pearson M, Dawson C, Moore H, Spencer S. Health on borrowed time? Prioritizing and meeting needs in lowborrowe 1993; 1: 45-54.

30 Cooke RWI. Trends in preterm survival and incidence of cerebral haemorrhage, 1980-89. Arch Dis Child 1991; 66: cerebral

31 Luker $\mathbf{K}$, Chalmers KI. Gaining access to clients: the case of health visiting. $\mathcal{F}$ Adv Nursing 1990; 15: 74-82.

\section{'Ecstasy', Ophelia, and the nightingale}

That unmatch'd form and feature of blown youth Blasted with ecstasy: $\mathrm{O}$, woe is me,

(Ophelia) Hamlet Act 3, scene 1

Is it hypocrisy to drink alcohol and condemn the use of 'Ecstasy'? Reports from the United States have suggested that Ecstasy (3, 4methylenedioxymethamphetamine, MDMA) is widely used and usually only mildly toxic. A recent paper in the Lancet from the National Poisons Information Service at Guy's Hospital, London (J A Henry and colleagues, 1992; 340: 384-7) describes experience during 1990 and 1991 and records seven fatal cases and five cases of severe acute toxicity in young people after apparently modest doses.

In the series of fatal cases there were five males and two females aged between 16 and 21 years. In two the dose is not stated but the other five had taken $1,2,3,3$, and 5 tablets, all of them at a party, club, or concert. One patient had a liver transplant after four days but died 18 days later. The remaining six died from 2.5 to 60 hours after admission to hospital. All had tachycardia and a temperature of $40^{\circ} \mathrm{C}$ or more at presentation. One had fixed, dilated pupils and severe cardiac arrhythmia and died after 2.5 hours. Six had seizures and three developed rhabdomyolysis, disseminated intravascular coagulation (DIC), and acute renal failure. Two were hypertensive and four hypotensive when first seen. The authors attribute the deaths to heatstroke caused by taking the drug in circumstances involving vigorous exercise (dancing), high ambient temperature, and inadequate fluid intake.

A 13 month old child who swallowed a single tablet of Ecstasy was described in detail in this journal $(1992 ; 67: 1114-5)$. Four other people aged 19 to 25 years took $2,2 \cdot 5,3$, and 3 tablets. Two developed rhabdomyolysis, DIC, and acute renal failure and one needed haemodialysis for 20 days. One was comatose and had diarrhoea and vomiting but recovered with forced diuresis and chlorpromazine. One had a subarachnoid haemorrhage within a few hours of taking the tablets. A further seven people aged 19 to 29 years developed hepatoxicity as a late complication. One died and one needed a liver transplant.

Is Ecstasy different from alcohol? The answer must be 'Yes' because the toxicity seen in this series was not dose related. Whereas the moderate 'social' use of alcohol is free of this kind of severe acute toxicity, there appears to be no 'safe' dose of MDMA. Taking a single tablet can kill. It looks as if we can continue to enjoy the Jacob's Creek dry red while advising against the use of Ecstasy and still avoid a charge of hypocrisy when, like Keats listening to his nightingale, we need 'A draught of vintage'

'That I might drink, and leave the world unseen, And with thee fade away into the forest dim:

Fade far away, dissolve, and quite forget

What thou among the leaves hast never known,

The weariness, the fever, and the fret

Here, where men sit and hear each other groan'. 